\title{
PORQUE ENSINO DO JEITO QUE ENSINO? REFLEXÕES SOBRE A PRÁTICA PEDAGÓGICA
}

Carmem Lúcia Ferreira ${ }^{1}$

Edlaine Silva Ribeiro ${ }^{2}$

Galsione Cruvinel da Silva ${ }^{3}$

RESUMO: Este ensaio de pesquisa bibliográfica tem como eixo central a relação das práticas de ensino, em escolas públicas, mais especificamente na educação infantil e no Ensino Fundamental. Traz uma reflexão acerca da postura do educador, enquanto agente de construção de conhecimentos na escola pública. Discute e debate acerca do conceito de capacitação de educadores e da produção de saberes, com base na visão de alguns estudiosos que trabalham o processo de ensinoaprendizagem e na concepção de como a escola concebe o "saber" e o que ela classifica como "ignorância". Questiona a forma com que é dirigida aos professores a formação continuada, os quais, na maioria das vezes, são obrigados a cumprir uma carga horária, sem uma discussão aprofundada sobre a necessidade da capacitação docente. Mais adiante é evidenciada a importância do processo de inovação, elaboração e reflexão acerca das práticas educativas, principalmente dos profissionais da Educação Básica, que tratam de sujeitos em fase de formação, de transformação, crianças e jovens, que merecem uma atenção especial por parte da escola. Enfoca ainda o modelo de educação formal e a necessidade da busca de outro paradigma educacional, visando inserir os educandos no processo de intervenção na escola, na vida e no mundo. Analisa, por fim, o processo de exclusão/inclusão, direcionado tanto aos educadores, quanto aos educandos, presentes nas instituições de ensino e nas políticas públicas.

Palavras-chave: Capacitação Docente. Construção de Saberes. Formação Continuada. Práticas Educativas.

\footnotetext{
${ }^{1}$ Graduanda Pedagogia UFMG

${ }^{2}$ Graduanda Pedagogia UFMG

${ }^{3}$ Docente UNIUBE
} 


\section{INTRODUÇÃO}

Este trabalho busca uma abordagem reflexiva acerca da prática pedagógica nas séries iniciais da educação básica. O foco será a Educação Infantil e o Ensino Fundamental, por se tratar de um público (os educandos) cada vez mais exigente no tocante à capacitação dos educadores que trabalham com este seguimento.

Hoje as escolas, especificamente as das redes públicas, trazem uma proposta de trabalho com um plano de ensino voltado não só para atender às necessidades básicas dos alunos, como por exemplo, permanecerem na escola por um período integral, somente enquanto seus pais ou responsáveis trabalham, mas para inserirse num processo de intervenção.

Notam-se alunos que saem da Educação Infantil, escrevendo seu nome, contextualizando histórias infantis, realizando atividades de ações práticas como "O Combate á Dengue", dentre outros.

Então, este ensaio vem no sentido de mostrar o quanto a educação voltada para as séries inicias, deve ser observada sob a ótica de um novo olhar, sobretudo, para os profissionais que almejam atuar neste setor.

A velha idéia totalmente equivocada de que trabalhar com "crianças" é mais "fácil", caiu por terra, pois ao contrário, este é um público que requer maior cuidado e atenção por parte dos professores.

Desta forma, a abordagem crítica dessa temática se faz mais que necessária, se faz imprescindível, pois, tratar das questões relacionadas às séries iniciais de escolarização significa estabelecer novos parâmetros, rever conceitos e, acima de tudo buscar novas práticas pedagógicas que, (re)signifiquem os conteúdos trabalhados com este público extremamente relevante.

\section{A PRÁTICA EDUCATIVA NA ESCOLA PÚBLICA}

O trabalho educativo com setores marginalizados da sociedade, ou setores populares requer uma reflexão sobre a escola tradicional ou formal, sobre a relação de ensino/aprendizagem e sobre os processos de exclusão/inclusão educacional e social.

Para tanto, é preciso considerar a escola da modernidade como fruto do processo de desenvolvimento da sociedade capitalista, o qual deriva do pensamento 
positivista. Este pensamento deu origem à racionalidade técnica e científica, originada a partir da idade das luzes, no continente europeu. Então, a escola da modernidade reproduz, fielmente, o discurso homogeneizador decorrente dessa racionalidade.

(FONSECA 2009, p.116) discorre sobre esta questão:

[...] a escola na sociedade capitalista reproduz a correlação de forças existentes nesta sociedade. Assim, ela acaba reproduzindo as ideias majoritárias do capitalismo, ou seja, a ideologia das elites detentoras do poder político e econômico. É lógico, que em seu interior existe o espaço de resistência, a mesma que atua no seio da sociedade capitalista; dessa maneira é preciso utilizar estes espaços para a propagação de uma proposta de ruptura com o discurso hegemônico existente em seu interior.

Neste contexto, a escola vem se reestruturando para atender as demandas da economia de mercado, base do atual modelo de desenvolvimento. Dessa "nova" organização escolar ocorre, simultaneamente, a perda de autonomia do educador, conforme enfatiza Mariano F. Enguita, 1991:

\begin{abstract}
A urbanização, a introdução das escolas completas e seriadas, as concentrações escolares, a expansão do setor público, a criação de escolas privadas para setores com poder aquisitivo alto e sua generalização para todos com a política de subvenções são os fatores que têm feito desaparecer o docente autônomo, inclusive o mestre público semiautônomo da zona rural.
\end{abstract}

De fato, a nova ordem estabelecida pelo racionalismo leva a conflitos, cada vez mais evidentes, entre as conseqüências deste pensamento e a realidade do cotidiano escolar. O pensamento positivista retoma com vigor o discurso homogeneizador da escola, como forma de legitimar os problemas sociais crônicos dos dias atuais.

Angel Pérez Gomes, 1995, (p.59), ilustra bem esta situação:

A realidade social não se deixa encaixar em esquemas preestabelecidos do tipo taxonômico ou processual. A tecnologia educativa não pode continuar a lutar contra as características, cada vez mais evidentes, dos fenômenos práticos: complexidade, incerteza, instabilidade, singularidade e conflitos de valores. (grifos do autor).

É com base nos elementos supra citados, que se deve analisar o trabalho educativo com os setores populares e a educação informal no contexto das escolas públicas. 
A prática educativa com os setores populares e/ou com as escolas públicas pressupõe o entendimento da rede de vivências sociais, como: desemprego, subnutrição, falta de condições de higiene, saúde, saneamento, fome, falta de carinho, amor, dentre outras. Neste caso, o educador deve estar aberto às relações aprender/ensinar e ensinar/aprender, o que significa colocar-se nas condições da realidade do cotidiano dos educandos, fazendo a relação entre as suas vivências sociais, sua realidade concreta com os conteúdos escolares, com os quais se trabalham.

Nesta situação, o cotidiano escolar possui aspectos singulares, conforme define Maria Teresa Esteban, 2003, (p.200-201):

\begin{abstract}
As questões se avolumam quando situamos a pesquisa no cotidiano da escola em que interagem sujeitos das classes populares. Pois o cotidiano é o tempo/lugar do pequeno, do desprezível, do sem-importância, do irrelevante, do episódico, do fragmento, do repetitivo. $E$ as classes populares também congregam os sujeitos sem importância, pequenos, desprezíveis. Fatos e pessoas que não correspondem às grandes narrativas que constituíram o discurso privilegiado das ciências, tornando-se invisíveis a uma ciência que não incorpora em suas análises o drama e a trama da sociabilidade dos simples, aqueles a quem a vida social imprimiu a aparência de insignificantes e que como insignificantes são tratados. (grifos da autora).
\end{abstract}

Portanto, esses aspectos levam à reflexão aprofundada sobre a exclusão sócio-educacional e a procura de caminhos que levem a escola a buscar métodos de inclusão, considerando as particularidades de cada educando, rompendo-se, assim, com o discurso homogeneizador de coisificação do homem.

Para se obter sucesso nessa prática educativa, torna-se imprescindível repensar a relação ensino/aprendizagem decorrente da escola tradicional, reprodutora do pensamento positivista. O educando deve ser compreendido em suas particularidades, como sendo diferente entre os supostamente iguais. Para tanto, deve-se valorizar os conhecimentos e experiências que ele já traz consigo, fruto de sua rede de vivências sociais, construída no cotidiano da sua realidade. Essas particularidades refletem os aspectos que levam à exclusão, os quais devem ser objetos de estudo dos educadores que se preocupam com a construção de um novo modelo escolar. 
Isabel Alarcão, 2001, adverte sobre a relação professor/aluno advinda da escola tradicional:

[...] O poder era apenas do professor porque era ele que detinha o saber, de uma forma absoluta, indiscutível e com autoridade. O aluno era o ignorante, o inculto, o aprendiz que era preciso ensinar, conduzir, disciplinar, controlar. Por isso, a relação do professor com os alunos era naturalmente distante, uma relação de superioridade e, em conseqüência, esperava-se dos alunos uma atitude de docilidade e de obediência, própria do discípulo, seguidor, imitador. O objetivo da aprendizagem visava à aquisição dos conhecimentos transmitidos e à imitação do mestre, como o modelo a seguir. Desse modo, - aluno deixava-se formar, modelar, de acordo com os "moldes" preestabelecidos. (Alarcão, 2001, p.98)

Portanto, para se trabalhar a prática educacional nos movimentos dos excluídos, faz-se necessário repensar atitudes e responsabilidades com o intuito de construir um modelo educacional eficaz, que seja capaz de romper com os dogmas e verdades arraigados da escola tradicional.

\section{SALA DE AULA: ELABORAR, REFLETIR, AGIR E INOVAR.}

As práticas pedagógicas nos dias atuais requerem muito mais que o texto exige, sobretudo, o contexto. Contextualizar significa trabalhar a realidade dos alunos dos setores populares, ou seja, fazer a ligação do conteúdo formal com a realidade desses educandos.

Dessa maneira estaremos (re)significando os conteúdos da educação formal, segundo a concepção que os sujeitos das escolas públicas têm diante da vida e do mundo. Inovar em sala de aula significa mostrar aos educandos a relação existente entre as partes, entre estas e o todo e entre o todo e as partes, conforme enfatiza Morin (2005):

O global é mais que o contexto, é o conjunto das diversas partes ligadas a ele de modo inter-retroativo ou organizacional. Dessa maneira, uma sociedade é mais que um contexto: é o todo organizador de que fazemos parte. O planeta Terra é mais do que um contexto: é o todo ao mesmo tempo organizador e desorganizador de que fazemos parte. $O$ todo tem qualidades ou propriedades que não são encontradas nas partes, se estas estiverem isoladas umas das outras, e certas qualidades ou propriedades das partes podem ser inibidas pelas restrições provenientes do todo. [...] É preciso efetivamente recompor o todo para conhecer as partes. (MORIN, 2005, p.37)

A formulação de Morin (2005) sintetiza o pensamento daqueles que querem inovar em sala de aula, isto é, indica que os problemas localizados nas comunidades 
nas quais estão inseridas as escolas públicas, estão ligados ao todo, ao global. Isso significa dizer que os problemas locais (cotidiano escolar) são um pequeno fragmento da sociedade. No mesmo sentido, Garcia (1998) complementa o pensamento de Morin:

É no cotidiano da sala de aula que a teoria é validada, iluminando a prática e fazendo-a avançar, confirmando-se ou sendo negada pelas evidências empíricas, o que desafia à construção de novas explicações. Daí que as discussões teóricas são todo o tempo reportadas à prática alfabetizadora trazida pelas professoras, num processo que visa à recuperação da unidade dialética teoria e prática. A teoria vai sendo atualizada e ganhando sentido e a prática vai adquirindo maior resistência. (GARCIA, 1998, p.23)

Os fragmentos textuais dos dois autores acima, se complementam no sentido da afirmação da necessidade da contextualização do objeto de estudo (conteúdos formais) e da consolidação da unidade teoria/prática. Assim, os conteúdos da escola tradicional perdem todo o sentido se estiverem fora do contexto da realidade cotidiana dos sujeitos que compõem os setores populares.

Desta forma, é imprescindível, como foi elencada no início do texto, a necessidade da formação continuada por parte dos educadores, visto que a rede de vivências que permeiam o interior da sala de aula é bastante complexa e como tal deve ser tratada.

Mesmo ao sabermos das inúmeras dificuldades que encontramos em nosso dia a dia, "numa sociedade excludente como a nossa, quando se é educador a sério, há que se trabalhar na tensão entre revolta/ descrença e luta/esperança" (GARCIA, 1998, p.18), objetivando alcançar a construção de uma escola de qualidade, democrática e verdadeiramente transformadora.

\section{“Capacitação” de Professores: Contextualizando a discussão.}

Nos últimos tempos tem-se observado certa "cobrança" por parte das secretarias de ensino em relação a tão falada "formação continuada" do professor. Ora, não se discute que aprimorar o que já estudamos seja de fundamental importância para sobrevivência no mercado de trabalho. E, com os educadores não é diferente. O que não é correto é fazer um curso por "obrigação" ou "imposição", em certos casos com promessas para quem concluir toda a carga horária exigida nos cursos de capacitação sem nenhuma falta.

É preciso lançar um olhar com maior criticidade a este respeito. Veja o que Garcia (1998) disserta a respeito, depois de dedicar aproximadamente mais de 20 
anos de militância em prol da educação infantil e ensino fundamental, intervindo no encorajamento na prática pedagógica de professoras alfabetizadoras:

"[...] o título "capacitação de professores" é revelador do preconceito, pois só pode pretender capacitar as professoras que as considera incapazes. E se elas são consideradas incompetentes é porque, equivocadamente, muitos desconsideram a prática como um espaço de produção de conhecimentos." (GARCIA, 1998, p.19)

Concordando com a autora, na maioria das vezes não se considera o interior da sala de aula como uma troca de aprendizagens. Isso não quer dizer que não devemos aprimorar nossos estudos e pesquisas, pois é através deles que avançamos e contribuímos para a melhoria de uma educação "igualitária", visto que todos perante a lei têm direito a educação, mas uma educação de qualidade, que busque (re)significar a vida dos nossos educandos e inseri-los no processo de intervenção no mundo, está além do papel. Esta prática se dá entre professor e aluno, se dá na forma de como o educador vê e percebe os sujeitos que compõe as instituições de ensino. Garcia (1998) continua sua reflexão:

O olhar ocasional torna-se olhar intencional e mais apurado, porque enriquecido pela teoria. Os ouvidos desatentos afinam-se e passam a ouvir distinguindo a sutileza das falas, conversas, risos, silêncios, gritos; o que antes parecia apenas ruído torna-se "entonação cheia de sentido" aos ouvidos da professora pesquisadora. (GARCIA, 1998, p.23)

É por intermédio dessas "evidências" é que vão surgindo para o educador a necessidade de buscar recursos para que sua prática avance e que seus objetivos sejam alcançados. Este é um bom caminho para se evitar uma frustração diante de um resultado esperado. Então, é preciso levantar algumas questões: qual o perfil do público que escolhi trabalhar? Nesta faixa etária, o que deve ser observado com maior frequência? O que estes sujeitos em formação esperam do professor?

Mészáros sustenta que,

[...] a educação deve ser sempre continuada, permanente, ou não é educação. Defende a existência de práticas educacionais que permitam aos educadores e alunos trabalharem as mudanças necessárias para a construção de uma sociedade na qual o capital não explore mais o tempo de lazer, pois as classes dominantes impõem uma educação para o trabalho alienante, com o objetivo de manter o homem dominado. Já a educação libertadora teria como função transformar o trabalhador em um agente político, que pensa, que age, e que usa a palavra como arma para transformar o mundo. (MÉSZÁROS, 2005, p.12) 
O autor defende que a busca pelo conhecimento deve ser constante, caso contrário não se faz educação. Reitero: é preciso diferenciar conhecimento de capacitação, visto que este conhecimento vai muito além dos muros da escola e da imposição que a sociedade capitalista nos impinge.

Fechando este tópico, mais uma vez recorre-se a Garcia.

\begin{abstract}
Colocamos em questão o que a escola considera "saber" e o que classifica como "ignorância", identificando o conteúdo emancipatório do que a escola chama de ignorância e denunciando o conteúdo ideológico do que denomina saber. Assim procuramos dialogar com outras formas de conhecimento, numa perspectiva multicultural que, mostrando as incompletudes de cada cultura, leva à tolerância a diferentes leituras e à abertura ao conhecimento do outro. (GARCIA, 1998, p.18)
\end{abstract}

Embora, com formulações diferentes os autores comungam da mesma idéia em relação à forma com que a educação é vista sob a ótica do capital e na perspectiva de uma educação libertadora. Dadas as observações, o termo ensino está presente ao longo do tempo, e era considerado na época tradicional, como uma vocação ou dom que os chamados Mestres tinham que possuir para ensinar as crianças. Passados algumas décadas, o ensino ficou sendo considerado como um ofício, ou seja, uma profissão que visa contribuir para a transmissão de conhecimentos. A partir desse momento surgia também à necessidade do professor está preparado tanto na sua formação acadêmica quanto em seus valores, ideias, concepções e ética.

Nesse sentido caracterizamos a importância do jeito em que o educador ensina, o modo que transmite o seu conhecimento, sua vivencia, experiências da vida escolar, sua cultura. Todos esses fatores contribuem com eficácia para a formação dos alunos fazendo com que eles se tornem cidadãos críticos e sociais no âmbito da sociedade.

Embora muitos professores só ensinem obedecendo aos critérios dos livros, não dando a importância no real sentido da aprendizagem, que nos remete a uma reflexão: porque ensino do jeito que ensino?

Assim, despertaremos no aluno a curiosidade de discernir e entender aspectos que levam a maneira e os métodos que o professor utiliza, aprimorando e renovando sua didática, buscando despertar cada vez mais o aluno crítico, para que continue a transformação da educação. E é nesse âmbito de trocas mutuas que 
consiste o compartilhamento entre aluno e professor que a educação continuara transformando.

\section{CONSIDERAÇÕES PARCIAIS}

Este ensaio fez uma importante reflexão acerca da postura do educador, enquanto agente de transmissão e de construção de conhecimentos e saberes. É preciso realizar algumas indagações a respeito da forma e a maneira com que percebemos a educação, é necessário reavaliarmos nossa prática, sob pena de ficarmos descontextualizados diante do processo histórico, cultural e social que marca os tempos presentes.

A arte de educar requer, dentre outros fatores, espírito de perseverança, de otimismo, de crença em nós mesmos, em nosso trabalho, em nossa capacidade de ser e estar neste planeta buscando cada vez mais fazer valer nossa intervenção.

Embora, seja óbvio e repetitivo, não se pode deixar de relembrar mais uma vez o descaso com que a categoria dos professores vem sendo tratada ao longo dos tempos, por intermédio de pressões diferenciadas, dentro e fora da sala de aula, a exemplo de diversos aspectos, tais como: baixos salários, salas de aulas superlotadas, falta de materiais didaticopedagogico, dentre inúmeros outros problemas.

Por essas razões é que conclamamos a todos os educadores comprometidos com a educação a participarem de suas instâncias de discussão e deliberação, como as Conferências de Educação, entidades de classes, sindicatos, etc. Raras são as oportunidades que temos para reivindicar o que nos é de direito. É hora de elaborar, refletir, agir e inovar.

Sabemos que algumas conquistas da nossa categoria são frutos das lutas democráticas dos professores, como os Parâmetros Curriculares Nacionais, que se consolidaram através de uma intervenção, onde havia um projeto, havia um objetivo comum, haviam forças unificadas buscando a melhoria da qualidade de ensino e a melhoria da qualidade de vida dos professores.

Por fim, esperamos ter levantado algumas indagações no sentido de acirrar o debate, visto que ele não se esgota aqui. É através dos embates que conseguimos 
avançar, reestruturar e permanecer neste grande palco de rede de vivências múltiplas, que é a sala de aula.

\section{REFERÊNCIAS}

ENGUITA, Mariano F. A Ambigüidade da Docência: entre o profissionalismo e a proletarização. Teoria e Educação, Porto Alegre, n.4, p.41-61, 1991.

ESTEBAN, Maria Teresa. Dilemas para uma pesquisadora com o cotidiano. In: GARCIA, Regina Leite (org.). Método: Pesquisa com o cotidiano. Rio de Janeiro: DP\&A, 2003, p.199-212.

FONSECA, Valter Machado da. A EDUCAÇÃO AMBIENTAL NA ESCOLA PÚBLICA: Entrelaçando saberes, unificando conteúdos. São Paulo/SP: Biblioteca24x7, 2009. v. 1. 230 p.

GARCIA, Regina Leite. Formação de Professoras Alfabetizadoras Reflexões Sobre uma Prática Coletiva. In: A FORMAÇÃO DA PROFESSORA ALFABETIZADORA: reflexões sobre a prática. Regina Leite Garcia (Org.). 2 ed. São Paulo: Cortez, 1998.

MÉSZÁROS, I. A Educação Para Além do Capital. Trad. Isa Tavares. Boitempo. São Paulo, 2005.

MORIN, Edgar. Os sete saberes necessários à educação do futuro. Trad. Catarina Eleonora F. da Silva e Jeanne Sawaya. 10 ed. São Paulo: Cortez; Brasília, DF: UNESCO, 2005.

PÉREZ GOMES, Angel. O pensamento prático do professor: a formação do professor como profissional reflexivo. In: NÓVOA, António. Os professores e a sua formação. Lisboa: Don Quixote, 1992. p.93-114.

TAVARES, J; ALARCÃO, I. Paradigmas de formação e investigação no ensino superior para o terceiro milênio. In: Alarcão, I. (org.). Escola reflexiva e nova racionalidade. Porto Alegre: ARTMED, 2001, p.98-114.

Recebido para publicação em: 20/12/2009

Aceito: 02/07/2010 